(NWTS) provides specialist retrieval service across the region. Patients are transferred to Alder Hey Children's hospital (AHCH), a cardiac surgical centre and Royal Manchester Children's hospital (RMCH) a cardiology centre. This review was undertaken to quantify current referral patterns and bed management.

Methods Retrospective review of NWTS retrieval of cardiac patients over the last 18 months.

Results

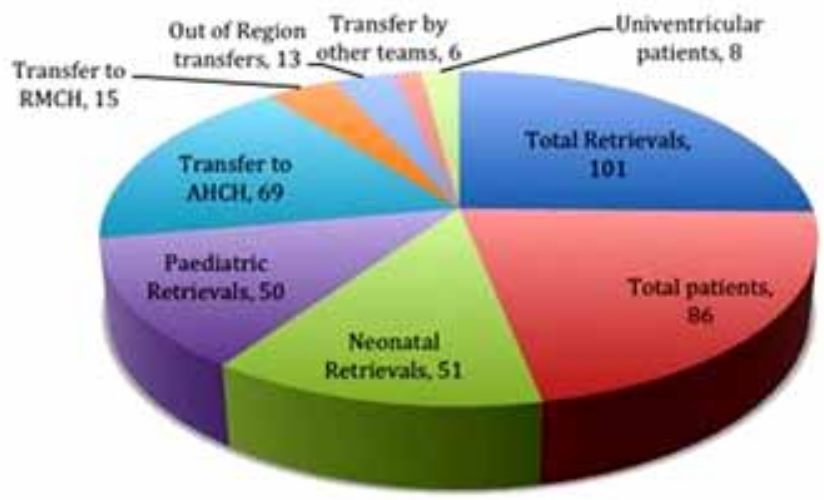

Abstract 968 Figure 1 Results

Abstract 968 Table 1 INTERVENTIONS

\begin{tabular}{lcc}
\hline INTERVENTIONS & REFERRING HOSPITAL & NWTS \\
\hline INTUBATION & 57 & 9 \\
DINOPROSTONE & 29 & 2 \\
INOTROPES & 23 & 10 \\
CENTRAL VENOUS ACCESS & 26 & 16 \\
INHALED NITRIC OXIDE & 0 & 4 \\
\hline
\end{tabular}

Median NWTS retrieval and stabilisation times were 238 and 118 minutes respectively. Only 4 neonates required an additional journey to a regional surgical centre. Total mortality (to discharge home) was $8 / 86 \sim 9.3 \%, 3$ post-operative deaths and 5 offered palliative care (inoperable lesion/other anomalies).

Conclusion For children with congenital heart disease, a regional specialist paediatric retrieval team can optimise bed management, minimise out of region transfers and ensure that time-critical care is delivered locally, safely and effectively.

\section{UNDER-REPORTED? A REVIEW OF UTILISATION OF THE PAEDIATRIC HIGH DEPENDENCY UNIT AT A DISTRICT GENERAL HOSPITAL}

doi:10.1136/archdischild-2012-302724.0969

'A Sylvan, ${ }^{2} \mathrm{M}$ Mukherjee, ${ }^{1} \mathrm{H}$ Mantle. 'Royal Albert Edward Infirmary; ${ }^{2}$ Paediatrics, Royal Albert Edward Infirmary, Wigan, UK

Background and Aims The 'High Dependency Care for Children' (Department of Health, 2001) report stipulates HDU level of care for all in-patient paediatric units. While the importance of regular audit is undisputed, concerns have been raised regarding the accuracy of data available to the Greater Manchester Paediatric \& Child Health Network (GMP\&CHN) and the consequences for optimal service provision.

This study aims to review and compare the utilisation of the Paediatric HDU at our District General Hospital with data available to the regional network (GMP\&CHN).

Methods Retrospective study of Paediatric HDU admissions between 02/09/2009 and 20/11/2011. Data was separated into 12 diagnostic categories and analysed for admission/readmission frequency and length of stay (defined as presence in HDU per calendar day) and compared with the respective figures of the GMP\&CHN 2011 regional audit of Paediatric HDU.

Results 208 patients were admitted 245 times, of which $39(18.75 \%)$ were readmissions. Mean length of stay per admission was 2.28 days (median: 2 days, range: 1-16 days). HDU occupancy rate over the study period (1,014 days) was $55.13 \%$ (559 days). For the period January-August 2011, GMP\&CHN figures show 23 admissions, a $40.35 \%$ underestimation of the actual figure ( 57 admissions).

Conclusions Paediatric HDU activity at our DGH has been underreported. This may not be an uncommon phenomenon nationwide.

We call for further review of HDU activity at units both regionally and nationally with a move towards agreed standards for data dissemination and reporting as per the Paediatric Critical Care Minimum Data Set.

\section{IMPROVING SPECIFICITY OF CLINICAL EVENT DETECTION IN THE NEONATAL INTENSIVE CARE UNIT (NICU)}

doi:10.1136/archdischild-2012-302724.0970

'V Gangadharan, ${ }^{2} \mathrm{~S}$ Mitra, ${ }^{2} \mathrm{H}$ O'Reilly, ${ }^{2} \mathrm{~T}$ Austin, ${ }^{1} \mathrm{AP}$ Gibson. ${ }^{1}$ Medical Physics and Bioengineering, University College London, London; ${ }^{2}$ Cambridge University Hospitals NHS Foundation Trust, Cambridge, UK

Background and Aims Continuous physiological parameter monitoring is routine in NICU. However, high false alarm rates exist that can lead to inappropriate responses from clinical staff.

At present, parameters are assessed independently to generate alarms. The positive predictive value can be increased in adult patients by combining the physiological parameters using statistical models ${ }^{1}$.

We have developed a multi-parameter model, designed for sick newborn infants, which produces alarms based on an integrated assessment of patient physiology. We hypothesized that this model would have greater specificity than conventional single channel alerts.

Methods Continuous physiological data (heart rate, respiration rate, oxygen saturation, blood pressure and temperature) were collected from 6 preterm infants, median gestation 26.1 weeks (range 24.3-28.9). The median period of data collection was 16.5 days (range 10.9-23.2). A mathematical model was developed using Matlab, which 'learnt' 1 hour of normal data in order to subsequently identify abnormal events in the remaining dataset. Adverse clinical events were identified retrospectively from patient notes. Results

Abstract 970 Table 1 Table comparing detection performance

\begin{tabular}{lccc}
\hline & Sensitivity & Specificity & $\begin{array}{c}\text { False positives } \\
\text { per hour }\end{array}$ \\
\hline Existing single-channel alert method & $100 \%$ & $0 \%$ & 1.8 \\
Proposed multi-parameter model & $99 \%$ & $17 \%$ & 0.1 \\
\hline
\end{tabular}

157 clinical events were obtained for analysis. The proposed model increases specificity of event detection, reduces false positives by a factor of 18 and maintains high sensitivity.

Conclusions This pilot study demonstrates that combining existing physiological data using a multi-parameter model improves the specificity of adverse event detection in the NICU.

${ }^{1}$ Tarassenko L et al. Br J Anaesth. 2006; 97:64-8.

\begin{tabular}{l}
\hline 971 NEONATOLOGY-OSTEOPATHY (NE-O) STUDY: RCT ON \\
THE EFFECT OF OSTEOPATHIC MANIPULATIVE
\end{tabular} TREATMENT ON LOS

doi:10.1136/archdischild-2012-302724.0971 
'A Accorsi, ${ }^{2} \mathrm{C}$ Lucci, ${ }^{1} \mathrm{G}$ Pizzolorusso, ${ }^{3} \mathrm{~L}$ Tubaldi, ${ }^{1} \mathrm{~F}$ Cerritelli, ${ }^{3} \mathrm{FP}$ Perri. ${ }^{1}$ European Institute for Evidence Based Osteopathic Medicine; ${ }^{2}$ Accademia Italiana Osteopatia Tradizionale Pescara; ${ }^{3}$ Neonatal Intensive Care Unit, Macerata Hospital, Macerata, Italy

Background and Aims The use of osteopathic manipulative treatment (OMT) in preterm infants has been documented and results from previous studies suggest the association between OMT and length of stay (LOS) reduction, as well as significant improvement in several clinical outcomes. The aim of the present study is to show the effect of OMT on LOS in a sample of premature infants. Methods A double blinded randomized controlled trial was conducted on preterm newborns admitted in a single NICU between 2010-2011. $\mathrm{N}=51$ subjects free of medical complications and with gestational age $>28$ and $<38$ weeks were enrolled and randomized in two groups: study group ( $\mathrm{N}=21)$ and control group $(\mathrm{N}=30)$. All subjects received routine pediatric care and OMT was performed to the study group for the entire period of hospitalization. Endpoints of the study included differences in LOS and daily weight gain.

Results Results showed a significant association between OMT and LOS reduction (mean difference between treated and control group: -1.787 ; $95 \%$ c.i. $-3.555,-0.0015$; $\mathrm{p}<0.05$ ). OMT was not associated to any change in daily weight gain.

Conclusions The present study confirms that OMT could play an important role in the management of preterm infants hospitalization.

\section{MANAGING ENT EMERGENCIES NEEDING TRANSFER TO PICU: THE EXTENDED TRANSPORT TEAM}

doi:10.1136/archdischild-2012-302724.0972

${ }^{1} \mathrm{M}$ Entwistle, ${ }^{2} \mathrm{~K}$ Parkins, ${ }^{3 R}$ Barber, 'S Santo. 'NWTS, CMFT; ${ }^{2}$ NWTS, Alder Hey Children's NHS Foundation Trust, Warrington; ${ }^{3 N W T S, ~ C M F T, ~ M a n c h e s t e r, ~ U K ~}$

Background Paediatric ENT emergencies are rare but can be lifethreatening and challenging to manage. In UK paediatric ENT services are centralised, and adult ENT surgeons and anaesthetist provide cover in local hospital (DGH). North West and North Wales Paediatric Transport Service (NWTS) UK is a specialist transport team.

Method Retrospective audit 12 months ENT transfers (NWTS database).

Results 74/932 (8\%) referrals had ENT diagnosis.

Feedback from DGH teams highlighted that advice from NWTS team including conference calls with Paediatric ENT helped optimise management.

Conclusion NWTS conference calls with Paediatric ENT specialists and local team improve patient management. Paediatric ENT consultants are occasionally required with NWTS team, providing expert advice and practical help. This data will help develop new regional intubation guidelines including recognition and management of the difficult paediatric airway.

\section{REGIONAL PAEDIATRIC INTENSIVE CARE (PIC) TRANSPORT SERVICES: BENEFITS OF 2 BECOMING 1 !}

doi:10.1136/archdischild-2012-302724.0973

B Lakin, K Parkins, C Walker, R Barber, S Santo, K Claydon-Smith. North West and North UK Paediatric Transport Service, Warrington, UK

Background Approximately 1.7 million children North West and North Wales (UK) and 600-700 are transferred annually from 31 hospitals into 2 regional PICUs.

Prior to 2010 specialist PIC transport teams were unit based but review (2007) revealed problems:

- Minimum 30\% PIC transfers by non-specialised teams (associated with adverse incidents)

- Poor access to clinical advice

- Delays finding PIC bed

- Delays mobilising specialist PIC transport team

- Adverse incidents associated with inexperienced medical personnel (specialist teams)

Regional Paediatric Transport Service (NWTS) started 2010 with a single point of contact providing advice, organisation transfer and PIC bed.

Methods Several database audits (first 12 months) to assess quality of retrievals compared to previous data.

Results $91.6 \%$ PIC transfers done by NWTS in first year (target > $85 \%)$.

Retrieval times (median) Mobilisation 29.5mins (pre NWTS 80mins); stabilisation 102 mins (pre NWTS 110mins); total retrieval time 201mins (pre NWTS 310mins)

Winter data consultant present $50 \%(n=40)$ retrievals - supporting inexperienced staff.

Snapshot (6 weeks) audit showed patient management advice was substantial and potentially avert admission. For example, 13 children were initially referred, but with advice over 3 (median) phone calls (range 2-8) remained in the local centre.

Better utilisation PIC beds refusal rate $5.8 \%$ versus $37 \%$ pre-NWTS.

Satisfaction survey (referring hospitals) demonstrated overall satisfaction excellent or good in domains including comparison with previous arrangements and clinical care.

Conclusions Our data suggest that improvement in quality has occurred since the launch of NWTS, including improved utilisation of regional PICU beds.

Abstract 972 Table 1 Results

\begin{tabular}{|c|c|c|c|c|c|c|}
\hline Causes & Infective & Neonate & Foreign Bodies & Elective & Injury & Post-Tonsillectomy \\
\hline Numbers & 36 & 13 & 10 & 8 & 4 & 3 \\
\hline Age & 5 months - 9yrs & $\begin{array}{l}5<24 \text { hrs old ( } 3 \\
\text { preterm) } 8 \text { older }\end{array}$ & 10 months- 14 yrs & 6 days-5yrs & $1-5 \mathrm{yrs}$ & \\
\hline Diagnosis & $\begin{array}{l}\text { Croup, tracheitis, } \\
\text { parapharyngeal } \\
\text { abscess }\end{array}$ & Various & $\begin{array}{l}4 / 10 \text { respiratory } \\
\text { arrest }\end{array}$ & $\begin{array}{c}\text { Tracheal stenosis, } \\
\text { malacia, cystic } \\
\text { hygroma }\end{array}$ & $\begin{array}{l}\text { Trauma, caustic } \\
\text { ingestion }\end{array}$ & 2 with pre-op OSA \\
\hline Treatment & $\begin{array}{l}\text { Steroids, nebulised } \\
\text { adrenaline } \\
+/- \text { antibiotics }\end{array}$ & & $\begin{array}{l}\text { Removal in tertiary } \\
\text { centre }\end{array}$ & $\begin{array}{l}\text { Transferred for } \\
\text { complex intervention }\end{array}$ & $\begin{array}{c}\text { Steroids } \\
+/- \text { antibiotics }\end{array}$ & \\
\hline Intubation & $\begin{array}{l}\text { 19/36 intubated 1/36 } \\
\text { LMA 16/36 resolved L } \\
\text { (not transferred) }\end{array}$ & $\begin{array}{l}\text { 11/13 } 1 \text { transferred } \\
\text { LMA (NWTS) } 1 \text { unable } \\
\text { to secure airway }\end{array}$ & $5 / 10$ & $\begin{array}{l}\text { All endotracheal tube } \\
\text { or tracheostomy }\end{array}$ & $4 / 4$ & $3 / 3$ \\
\hline $\begin{array}{l}\text { Paeds ENT advice } \\
\text { (Present) }\end{array}$ & $4 / 36(2)$ & 13/13 (3) & $10 / 10(0)$ & $8 / 8(0)$ & $4 / 4(0)$ & $3 / 3(0)$ \\
\hline
\end{tabular}

